\title{
KNOWLEDGE, ATTITUDE AND PERCEPTION (KAP) OF FARMERS FOR USING INFORMATION AND COMMUNICATION TECHNOLOGY
}

\author{
IN AGRICULTURE IN PUNJAB, INDIA
}

\section{GAGANDEEP KAUR GREWAL ${ }^{1}$ \& KIRAN JYOTI ${ }^{2}$}

${ }^{1}$ Research Scholar, I.K.G.P.T.U. Jalandhar, and Assistant Professor Department of CSE, Guru Nanak Dev Engineering College, Ludhiana, Punjab, India

${ }^{2}$ Assistant Professor Department of I. T., Guru Nanak Dev Engineering College,

Ludhiana, Punjab, India

\begin{abstract}
Information and communication technology (ICT) plays an important role in improving farming practices across the globe. However, the use of ICT has been limited in the farmers of the developing world. The current study was planned to assess knowledge, attitude and perception (KAP) of farmers for using information and communication technology in agriculture in Punjab state of India. A structured questionnaire was prepared in this KAP study. One hundred and fifty farmers with different landholdings consented and participated in this study. However, $53.33 \%$ small scale farmers and $60 \%$ of medium scale farmers were regularly using mobile phones. The results indicate that sharing of agricultural information through mobile applications (apps) could better facilitate farmer requirement than other sources of ICT.
\end{abstract}

KEYWORDS: Agriculture, Communication, Information Technology \& Mobile App

Received: Oct 21, 2015; Accepted: Oct 29, 2015; Published: Nov 04, 2015; Paper Id.: IJCSEITRDEC20152

\section{INTRODUCTION}

Punjab, the state of green revolution in India, is no more a state of ever-booming agriculture. Many factors such as decreasing land holdings, stagnation in crop productivity, increasing input costs, fluctuating crop prices and climate change etc. affects farm income in many ways particularly marginal and small farmers. The number of marginal and small land holdings ( $<2$ hectares of land) has increased from 83.5 million to more than 117.6 million since last two decades (Sukhpal and Shruti, 2014). However, the number of marginal and small holdings has decreased from half a million to 0.36 million during the same period in Punjab, India (Sukhpal and Shruti, 2014). At the same time, the number of semi-medium (2-4 hectares), medium (4-10 hectares) and large (> 10 hectares) land holdings have increased from 0.62 million to 0.69 million in Punjab during past 20 years (Sukhpal and Shruti, 2014).

A survey done in India on wheat farmers who do not use herbicides for the control of weeds revealed that lack of knowledge was the main reason for non-adoption (41\%). Other significant factors were lack of skill (13\%) and lack of guidance $(24 \%)$. About $65 \%$ of the farmers suggested that extension systems should publicize the method of chemical use and highlight its instruction (Singh and Varshney, 2010). Lack of technology is also one of the major roadblocks for improving the productivity of agriculture. 
The farmers need the right information for successful farming that is easily available. To break the communication barrier and knowledge gap, the Government of India has started farmers' portal for its all states. However, few farmers use this online portal or visit local agriculture universities to get expert advice.

The agricultural practices are changing every day. Lack of recent agricultural knowledge and expert advice to the farming community could negatively impact farm production. e-Agriculture involves the conceptualization, design, development, evaluation and application of innovative ways to use information and communication technologies (ICTs) in the rural domain, with a primary focus on agriculture (Chandra and Malaya,2011). The advancement of ICT can be utilized for providing accurate and timely relevant information and services to the farmers, thereby facilitating an environment for remunerative agriculture (Singhal et al. 2011). The current study was planned to study the use of ICT tools in agriculture sector in Punjab with special emphasis on the small and marginal farmers.

\section{MATERIALS AND METHODS}

Manual method which is the most popular method adopted by traditional farmers is not sufficient. To study Information and communication techniques as agriculture tool for the management of crops has been taken through field survey. For studying the benefits of data mining applications using ICT, the survey was conducted in year 2014. The farmers from three districts namely Ludhiana, Moga and Sangrur were chosen for the survey. Five villages were randomly selected from one district and ten farmers from each village were randomly selected. Fifty (50) farmers were randomly selected making a total of 150 respondents for the study. The data from all the available families in the selected villages were collected through interview method on specially structured questionnaire. Out of these, 75 were marginal farmers (<1 ha) and 75 were small farmers (1-2 ha) were selected. Also youth of rural agrarian Punjab was asked questions and on the spot assessments regarding the effects of mobile apps on use of insecticides, crop yield (data not shown) etc. was made. The analytical tools used for this study include ms-excel, MATLAB. This survey was conducted in three districts of Punjab and the results revealed that among various ICT tools like TV, internet, mobile, radio etc, $53.33 \%$ of small scale and $60 \%$ of medium scale farmers use mobile phones. Table 2 reveals that not all farmers visit agriculture experts and agriculture universities. And kisan melas are mostly visited by farmers in both categories, which are not very frequent in occurrence. So due to reluctance in visits and expert meetings; mobiles can help a lot in farming and creating awareness about various issues.

\section{RESULTS AND DISCUSSIONS}

The survey indicated that use of mobile based awareness applications can be beneficial to the farmers. Already available tools like television, radio are used but not more than $15 \%$ and 5\%, respectively. When discussed about the reasons, farmers mentioned that they do not get proper broadcasting time information. Often they miss the time of broadcasting. Some farmers felt due to their busy schedules in the evening they do not sit and watch TV or listen to radio programs. They believe that sometimes their junk programmes are not specific to their needs. They have to wait long for their specific crop programs and which rarely they watch/listen. Sometimes power supply was also a constraint. Documented materials like periodicals/journals/newspapers also are not very popular (Table 1). Educated farmers make use of newspaper (30-32\%). But agriculture periodicals/magazines are very less popular (3-5\%). In villages they do not reach well in time. Finally postal delay led to over of particular and relevant season of a crop. When asked about mobile phones, $53-60 \%$ farmers answered affirmative about its use for various purposes. Only five to ten per cent farmers have access to computers at home (Table 1). Though internet access is less on both (mobile and computer) above mentioned ICT tools, but 
farmers are aware of internet advantages through youth. Farmers did not prefer to visit any State Agricultural University site for up gradation of knowledge.

Approximately $9.33 \%$ medium scale farmers visit Krishi Vigyan Kendras and Experts. And 9-13.33\% of famers visit kisan melas from where they get vast knowledge, seeds, tools information, etc. $10 \%$ of medium scale farmers rely on private dealers which is again less in small scale farmers.

During the conduct of this survey, farmers were made more aware of techniques which can help them in their agrarian processes. They participated enthusiastically and suggested various needs and requirements. These can be met by mobile apps. Through mobiles, farmers can get any particular information at any time from subject matter expert. Also alerts (weather forecast/ outbreak) and updates can be shared on mobile apps. Such apps can be changed from time to time according to the client's demand. Since large data is documented in the form of journals/magazines/package of practices, it needs to be mined and then only optimised result for the farmers' query can be extracted. Using data mining techniques like $\mathrm{k}$ mean clustering, the $k$ nearest neighbour, artificial neural networks and support vector machines, etc could be used to improve data extraction methods. Data discovery (figure 1) process comprises six phases: Data selection (about specific items or categories of items), data cleansing (correction of invalid data), enrichment (enhancement of data with additional knowledge), data transformation (to reduce the amount of data), data mining (new knowledge discovered using associative rules/sequential patterns/classification techniques) and display (in the form of list, graphs, tables, etc) of discovered knowledge. With the help of data mining, farmers are benefitted and will help in making farming more remunerative.

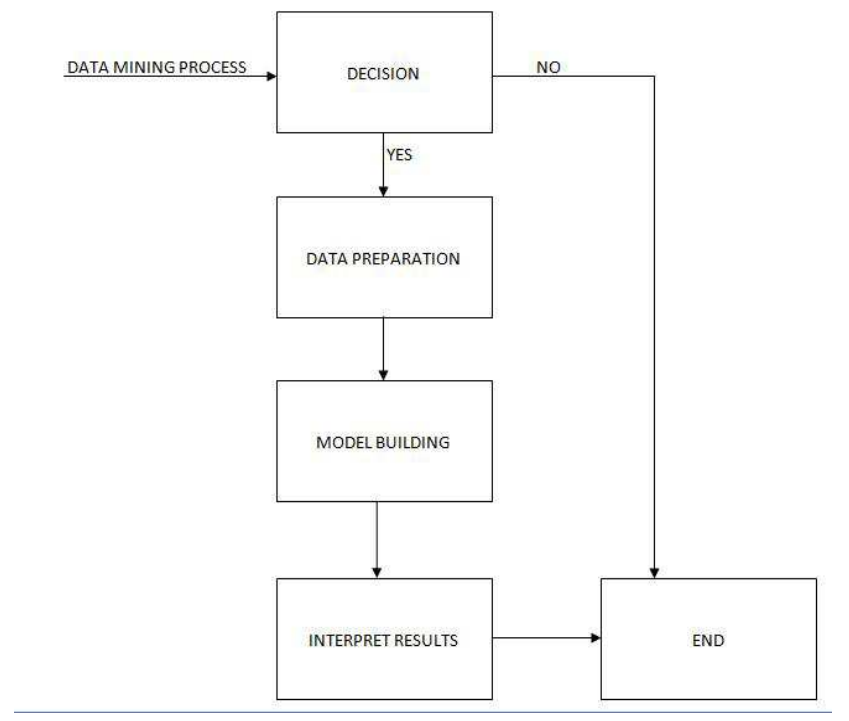

Figure 1: Flow Chart of Data Mining Process

Hence it is necessary to develop more efficient technological intervention like mobile app which should be introduced so that proper practices for raising good crop should be adopted by the farmers so that the farming will become remunerative.

Study revealed that almost all of the Indian farmers, majority of which are even small scale farmers afford mobile technology. These small scale farmers as such don't have access to personal computers, laptops, e-mails, journals etc. Mobiles are commonly used by small and medium scale farmers. Much research has been carried out in field crops but their implementation in field is still lacking. 


\section{CONCLUSIONS}

There is a dire need to introduce technology through mobile app in Punjab for obtaining good yields. By providing guidance on appropriate crop production practices through high tech technologies, there is considerable scope for management in every cop production technique which is a pre-requisite for obtaining good returns and enable farmers to make more efficient use of all resources. Making information available to farmers in the form of simple decision tools like mobile will make a substantial contribution in reducing production costs and crop losses. The study will contribute towards the development of decision tools.

Table 1: Use of Information and Communication Technology in Agriculture

\begin{tabular}{|l|c|c|}
\hline \multicolumn{1}{|c|}{ Type of ICT } & \multicolumn{2}{c|}{ Type of Farmers } \\
\hline & $\begin{array}{c}\text { No. of Small } \\
\text { Scale Farmers }\end{array}$ & $\begin{array}{c}\text { No. of Medium } \\
\text { Scale Farmers }\end{array}$ \\
\hline Newspaper & 30 & 32 \\
\hline Periodical/Agriculture magazines & 3 & 5 \\
\hline TV (Agriculture Programme) & 15 & 10 \\
\hline Radio (Agriculture Programme) & 5 & 2 \\
\hline Availability of Mobile phones & 40 & 45 \\
\hline With internet & 5 & 5 \\
\hline Without internet & 15 & 20 \\
\hline Availability of Computer & 5 & 10 \\
\hline With internet & 2 & 5 \\
\hline Without internet & 3 & 2 \\
\hline $\begin{array}{l}\text { Information through } \\
\text { mobile phone call }\end{array}$ & 2 & 5 \\
\hline SAU website & 0 & 0 \\
\hline
\end{tabular}

Table 2: Dependency for Source of Information of Agriculture

\begin{tabular}{|l|c|c|}
\hline \multicolumn{1}{|c|}{ Type of ICT } & $\begin{array}{c}|c| \\
\text { Nype of Small Scale } \\
\text { Farmers (\% age) }\end{array}$ & $\begin{array}{c}\text { No. of Medium Scale } \\
\text { Farmers (\% age) }\end{array}$ \\
\hline $\begin{array}{l}\text { Visit to Agricultural } \\
\text { Experts }\end{array}$ & 4 & 7 \\
\hline Visit to KVK's & 3 & 7 \\
\hline Kisan Melas & 7 & 10 \\
\hline $\begin{array}{l}\text { Private } \\
\text { Companies/Local } \\
\text { Dealers }\end{array}$ & 5 & 7 \\
\hline
\end{tabular}

\section{REFERENCES}

1. Singh P K and Varshney J G 2010. Survey of adoption level of chemical weed control technology in wheat crop at farmers' field. Biennial Conference of Indian Society of Weed Science.

2. Savary S, Srivastava $R K$, Singh H M and Elazegui F A 1997. A characterisation of rice pests and quantification of yield losses in the rice-wheat system of India. Crop Protect. 16, 387-398.

3. Chandra, D.G.; Malaya, D.B., "Role of e-Agriculture in Rural Development in Indian Context," Emerging Trends in Networks and Computer Communications (ETNCC), 2011, vol., no., pp. 320, 323, 22-24April2011 doi: 10.1109/ETNCC.2011.6255913.

4. Singhal, M.; Verma, K.; Shukla, A., "Krishi Ville - Android based solution for Indian agriculture," Advanced Networks and Telecommunication Systems (ANTS), 2011 IEEE 5th International Conference, pp.1, 5, 18-21 Dec. 2011 doi: 10.1109/ANTS.2011.6163685. 
Knowledge, Attitude and Perception (KAP) of Farmers for using Information and Communication Technology in Agriculture in Punjab, India

5. Jorquera, H., R. Perez, A. Cipriano and G. Acuna, 2001. Short term forecasting of Air Pollution Episodes. In: Environmental Modeling, Zannetti, P.(Edi).WIT Press, UK.

6. Rajagopalan, B. and U.Lall, 1999. A $K$-nearest neighbour simulator for daily precipitation and other weather variables. Water Resour. Res., 35: 3089-3101.

7. Sukhpal S., Shruti B., 2014. Depeasantization in Punjab: status of farmers who left farming. Current Science, Vol106. Issue 10, p1364-1368. 5p. 
